\title{
Water hardness removal by coconut shell activated carbon
}

\author{
Cecilia Rolence, Revocatus Lazaro Machunda, Karoli Nicholas Njau* \\ Department of Water and Environmental Science and Engineering, Nelson Mandela African Institution of Science and Technology \\ (NM-AIST), Arusha, Tanzania \\ Email address: \\ ceciliarolence@yahoo.com (C. Rolence), revocatus.machunda@nm-aist.ac.tz (R. L. Machunda), karoli.njau@nm-aist.ac.tz (K. N. Njau)
}

To cite this article:

Cecilia Rolence, Revocatus Lazaro Machunda, Karoli Nicholas Njau. Water Hardness Removal by Coconut Shell Activated Carbon. International Journal of Science, Technology and Society. Vol. 2, No. 5, 2014, pp. 97-102. doi: 10.11648/j.ijsts.20140205.11

\begin{abstract}
The present study reports the water softening by adsorption of hardness ions onto Coconut Shell Activated Carbons (CSAC). Characterization of CSAC was identified by FT-IR and SEM techniques. Batch experiments were carried out to determine the effect of various adsorbent factors such as adsorbent dose, initial $\mathrm{pH}$, contact time, and temperature, on the adsorption process using synthetic and field collected water samples. Removal efficiency at nearly neutral $\mathrm{pH}$ of 6.3 for both synthetic and field collected water samples were $60 \%$ and 55\% respectively. Temperature study (303 K-333 K) shows that the softening process in synthetic and field hard water is endothermic as removal efficiency was increasing from $40 \%$ and $29 \%$ at $303 \mathrm{~K}$ to $47 \%$ and $38 \%$ at $333 \mathrm{~K}$ respectively. Removal efficiency increases with the increase in contact time and adsorbent dose until 15 hours and $0.24 \mathrm{~g} / \mathrm{cm}^{3}$ respectively, for both field and synthetic hard water, which was considered to be maximum. Equilibrium isotherms have been analyzed using Langmuir and Freundlich isotherm models, and both Freundlich and Langmuir isotherm models fit to explain the adsorption behavior of hardness ions onto CSAC.
\end{abstract}

Keywords: Activated Carbon, Water Hardness, Coconut Shell, Adsorption, Removal Efficiency

\section{Introduction}

Among the various known forms of water contaminants, Calcium and Magnesium salts are of great concern since they lead to water hardness. By definition, water hardness is a measure of the quantity of divalent ions such as calcium and magnesium in water [1]. Water hardness problem is reported to exist in various places around the world, including Tanzania. Coastal and central regions of Tanzania are significantly affected by this problem, the reason behind is rock type, sedimentary rock, which is rich in Calcium and Magnesium [2, 3]. The latter ions dissolve easily in to the groundwater and make them hard [4].

In daily uses, hard water is associated with number of challenges that include scaling in boilers, washing machines and pipes [5], difficult lathering with soap, undesirable spots on sinks and clothes as well as toughening of skin and hair [6]. Hard water is said to cause serious health problems such as urolithosis, cardiovascular disorder, kidney problems, anencephaly and cancer [1]. Additionally, WHO reports that excess intake of calcium is associated with kidney stones and that of magnesium leads to diarrhea and laxative effect due to change in bowel habit [7].

Because of the challenges raised by hardness in water, immediate measures to soften water are inevitable. Currently, there are various techniques that have been put in place to solve the issue. Ion exchange [8], electro-based techniques [9] and membrane filtration [10] are among the techniques having so far been applied. However, high costs in installation, operation and maintenance [11] hinder its mass application especially in third world countries like Tanzania.

Water softening by adsorption using agricultural wastes based activated carbon as adsorbent seems to be potential in the sense that the agricultural wastes are locally and cheaply available. Coconut shells are agricultural wastes that mainly disposed after extraction of their inner contents. These wastes can be converted to useful activated carbon which in turn can be used to treat water [12]. Water softening by Coconut Shells Activated Carbon (CSAC) is not yet reported to be done. In the present paper, CSAC are being tested to establish their performance in softening hard water. 


\section{Materials and Method}

\subsection{Adsorbent}

Coconut Shell Activated Carbons (CSAC) were bought from KWHB Company, China. They were in granular form with the average particle size of $2.26 \mathrm{~mm}$ diameter and used directly without any further grinding and sieving.

\subsection{Characterization of Adsorbent}

Surface morphology analysis of adsorbents was carried out by Scanning Electron Microscopic (SEM) technique using FE-SEM, HITACHI S-4800. Fourier Transform Infrared (FTIR) analysis to determine functional groups on the surface of adsorbents was carried out using Hanyang university spectrometer with wave number ranging from 500 to $4250 \mathrm{~cm}^{-1}$.

\subsection{Adsorbates}

Synthetic hard water was prepared as instructed by Window on State Government [13] whereby $1.19 \mathrm{~g}$ of $\mathrm{CaCl}_{2}$ and $1 \mathrm{~g}$ of $\mathrm{MgSO}_{4}$ were dissolved in a litre of deionized water to make a water with hardness of $1214.8 \mathrm{mg} / \mathrm{L}$ as $\mathrm{CaCO}_{3}$ and this served as a stock solution. Field water of hardness $368 \mathrm{mg} / \mathrm{L}$ was collected from Kimani well located in Kisarawe district, Coast, Tanzania and stored in a temperature below $4^{0} \mathrm{C}$ to prevent microbial activities.

\subsection{Batch Experiments}

Batch adsorption experiments were conducted to examine adsorption behavior of CSAC on hardness removal under different adsorption condition. Adsorption studies were carried in different conditions namely adsorbent dose $\left(0.06-0.3 \mathrm{~g} / \mathrm{cm}^{3}\right)$, initial hardness $(552-936 \mathrm{mg} / \mathrm{L})$, contact time (3-15 hours), $\mathrm{pH}$ (2-12) and temperature (303-333 K). In each experiment, a known amount of CSAC was contacted with $50 \mathrm{ml}$ of desired hard water with known $\mathrm{pH}$ and agitated in a Thermo Scientific MaxQ 5000 shaker at a speed of $150 \mathrm{rpm}$ at a regular interval of time of 4 hours. The solutions were filtered by using Whatman filters and filtrates were collected for analysis. In each experiment the conditions were kept constant except for the one in which its effect is studied.

\subsection{Adsorption Isotherm Study}

Adsorption isotherm experiments were carried out at natural $\mathrm{pH}$ (6.3) of the samples by contacting a fixed amount of adsorbent $(8 \mathrm{~g})$ with $50 \mathrm{~mL}$ of water having hardness in the range of $552-936 \mathrm{mg} / \mathrm{L}$. The mixture was agitated for 15 hours which was found to be equilibrium time for adsorption of hardness ions onto CSAC. The concentration in the supernatant solution and in the adsorbent was analyzed. Langmuir and Freundlich isotherm models were applied to relate the distribution of hardness ions between liquid phase and solid phase [14]. Freundlich isotherm is valid for a heterogeneous adsorbent surface with a non-uniform

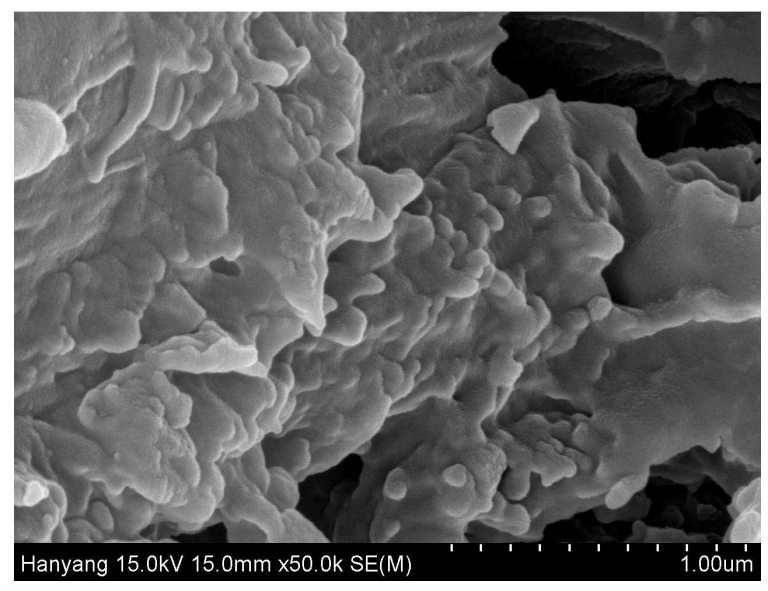

Fig 1. SEM image of CSAC

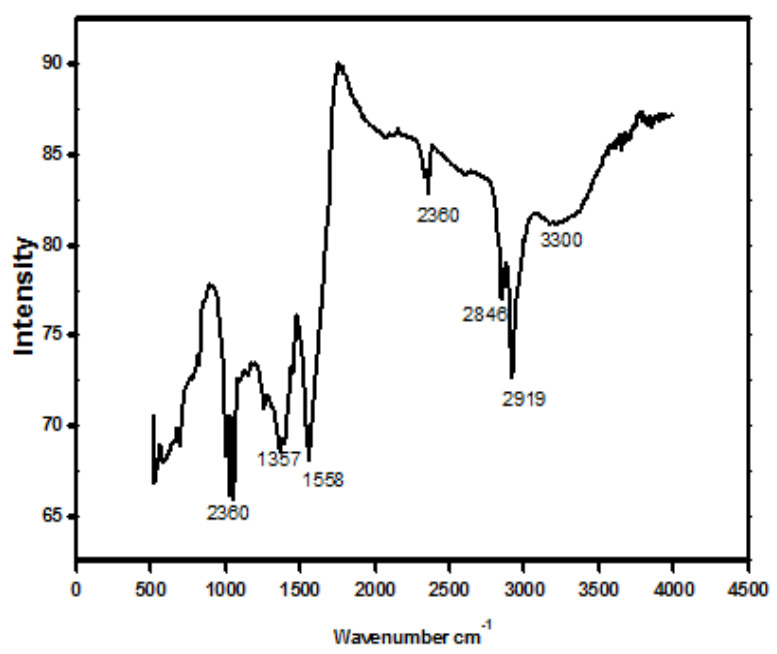

Fig 2. FT-IR spectrum for CSAC

distribution of heat of adsorption over the surface [15] while Langmuir is valid for homogeneous adsorbent surface [16].

\subsection{Analysis}

Hardness in water before and after equilibrium was determined by EDTA titration as described by Cash [17]. The $\mathrm{pH}$ of water was measured with a Hanna $\mathrm{pH}$ meter. The percentage removal of hardness was calculated using the following relationships:

$$
\% \text { removal }=\frac{C_{i}-C_{f}}{C_{i}} \times 100[18]
$$

Where, $C_{i}$ and $C_{e}$ are the initial and final hardness in $\mathrm{mg} / \mathrm{L}$ respectively. Origin Pro 8 software and Ms. Excel were used in statistical analysis and drawing graphs.

\section{Results and Discussion}

\subsection{Characterization of CSAC Adsorbent}

Scanning Electron Microscope (SEM) was used to observe the pore structures of the activated carbon. Pores present on CSAC adsorbent act as the active sites for adsorption and increase surface area. Large pore structures 
were developed during activation process of the said adsorbent as seen on the SEM image. Earlier feature explains high capability of CSAC adsorbent observed during batch experiment on water softening. The Scanning Electron Microscope images of activated carbon produced from coconut shell activated carbon is shown in fig. 1. The FTIR technique is an important tool to identify the characteristic functional groups which are vital in adsorption of hardness ions. Fig. 2 is FT-IR spectrum for CSAC. Adsorption at 1100 might be due to the vibration of alkoxy group $(\mathrm{C}-\mathrm{O})$. Alkane $(\mathrm{C}-\mathrm{H})$ stretch is indicated by presence of band at 2846 and $2919 \mathrm{~cm}-1$. The sharp absorption band at $1357 \mathrm{~cm}-1$ is ascribed to nitro group $(\mathrm{N}-\mathrm{O})$. The region of the spectrum of $2360 \mathrm{~cm}^{-1}$ is attributed to $\mathrm{C} \equiv \mathrm{N}$. The region of the spectrum of $1558 \mathrm{~cm}^{-1}$ is due to primary amine $(\mathrm{N}-\mathrm{H})$. A broad adsorption peak appeared at $3300 \mathrm{~cm}^{-1}$ is corresponding to the stretching of $\mathrm{O}-\mathrm{H}$ functional group. Identified functional groups are likely to account for the adsorption of hardness ions onto the adsorbent surface, hence high efficiency in water softening.

\subsection{Adsorption Trends between Field Water and Synthetic Water}

Although adsorption of hardness ions from field and synthetic water gave similar trend, the removal efficiency varied remarkably. Removal efficiency in synthetic water found to be higher than in field water. According to Sherene [19], ionic strength of the solution tends to influence the adsorption of the metal ion onto the adsorbent. In this regards, the higher the ionic strength, the lower the adsorption of metal ions. Since field water comprise of different ionic contaminants, its ionic strength is obviously high compared to that of synthetic water.

Therefore, Presence of other ions reduces the ability of hardness ions to adsorb onto the CSAC.

\subsection{Effect of Contact Time on Hardness Removal}

The effect of contact time was studied at of $30^{\circ} \mathrm{C}$, at intervals of 3 hours. Fig. 3 shows the relationship between

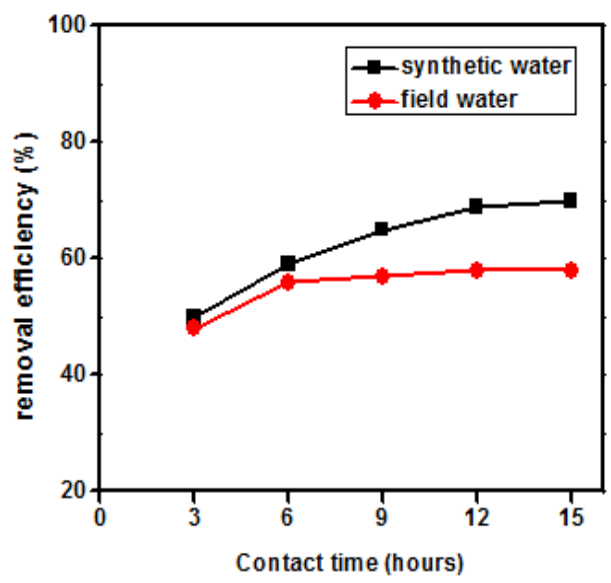

Fig 3. Effect of contact time on hardness removal by CSAC: temperature $=303 \mathrm{~K}$, hardness $864 \mathrm{mg} / \mathrm{L}, C S A C$ dose $=0.16 \mathrm{~g} / \mathrm{cm}^{3}, \mathrm{pH}=6.3$ contact time and hardness removal efficiency. Observation reveals that the removal of hardness ions increased with increasing contact time. The percentage hardness removal approached equilibrium within 10 hours. Further increase in contact time did not show significant change in hardness. The trend was similar in both synthetic and field water. This might be due to the fact that, large number of vacant surface sites is available for the adsorption during the initial stage and with the passage of time. After some times, repulsive forces between solute molecules on solid phase and liquid phase create difficultness for the solute molecules to occupy remaining vacant surface sites.

\subsection{Effect of Temperature on Hardness Removal}

Effect of temperature on adsorption of the hardness ions onto CSAC was studied by conducting different sets of experiments at different temperatures that are 303, 313, 323 and $333 \mathrm{~K}$ and it is found in fig. 4. It was indicated that adsorption of hardness ions increases slightly with the increase in temperature. Possible reason for this observation is swelling of the adsorbent that in turn lets more active sites available for hardness ions adsorption. In addition to that, the latter observation show shat the adsorption of hardness ions by CSAC is endothermic because adsorption increases with the increase in temperature.

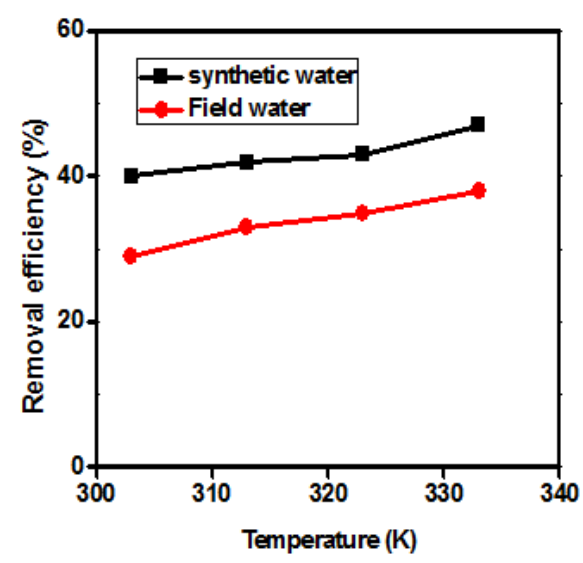

Fig 4. Effect of temperature on hardness removal by CSAC: contact time $=4$ hours, hardness $864 \mathrm{mg} / \mathrm{L}, \mathrm{CSAC}$ dose $=0.16 \mathrm{~g} / \mathrm{cm}^{3}, \mathrm{pH}=6.3$

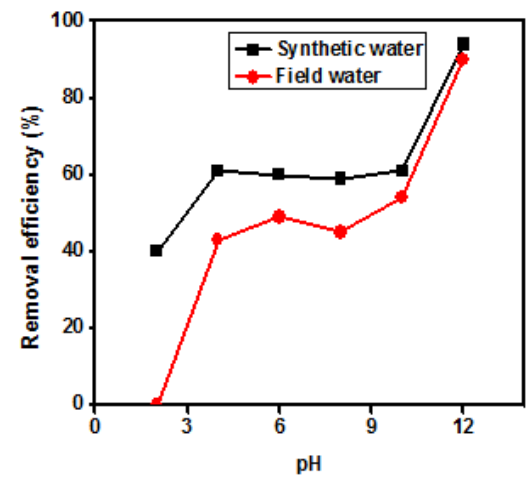

Fig 5. Effect of initial $p H$ on hardness removal by CSAC: contact time $=4$ hours, hardness $864 \mathrm{mg} / \mathrm{L}, C S A C$ dose $=0.16 \mathrm{~g} / \mathrm{cm}^{3}$, temperature $=303 \mathrm{~K}$ 


\subsection{Effect of pH on Hardness Removal}

The $\mathrm{pH}$ of a solution is an important parameter in the adsorption process [12]. Fig. 5 shows effect of $\mathrm{pH}$ on adsorption onto CSAC. During this study, results revealed that the removal of water hardness ions was strongly dependent on the $\mathrm{pH}$ of the solution. This is because variation of hydrogen ion concentration affects the number of metal ions binding sites on the adsorbent surface. That is to say, at lower $\mathrm{pH}$, the surface of the adsorbent is surrounded by hydrogen ions $\left(\mathrm{H}^{+}\right)$. The latter prevents adsorption of hardness ions on to the binding sites of adsorbent through repulsion [20] and the concentration of $\mathrm{H}^{+}$decreases with increase of $\mathrm{pH}[21]$.

The initial $\mathrm{pH}$ of water samples was varied from 2 to 12 . There was an increase in hardness removal at the $\mathrm{pH}$ from 2 to 4 . This might be due to the fact that as $\mathrm{pH}$ increases, the competition between hydroxonium ions, $\mathrm{H}_{3} \mathrm{O}^{+}$, and positively charged metal ions, for this case $\mathrm{Ca}^{2+}$ and $\mathrm{Mg}^{2+}$ at the surface of CSAC adsorbent decreases [22].For that reason, there is a likelihood of hardness ions $\left(\mathrm{Ca}^{2+}\right.$ and $\left.\mathrm{Mg}^{2+}\right)$ to be adsorbent in large quantity with the increase in $\mathrm{pH}$. At the $\mathrm{pH}$ of 5 to 10 hardness removal efficiency was observed to be almost constant. Trend of this nature is likely to be caused by presence of nearly equal concentrations of $\mathrm{H}_{3} \mathrm{O}^{+}$ and $\mathrm{OH}$ ions in the bulk solution that affect the polarity of adsorbent making it almost too neutral to adsorb more ions. But exponential increase of removal efficiency was observed from the $\mathrm{pH}$ of 10 to 12 . This might be due to the increase of hydroxyl ions $(\mathrm{OH})$ concentration in the solution that increases negativity of the adsorbents.

Highest removal efficiency was $94 \%$ that was achieved at the $\mathrm{pH}$ of 12 . The later seems to be not economical and safe as it will need to raise the $\mathrm{pH}$ of water before softening and reduce it to neutral $\mathrm{pH}$ after softening. In a long run of doing so, $\mathrm{pH}$ adjusting chemicals are introduced in the water and this reduces the safety of that water. Not only that but also extra expenses have to be incurred to buy chemicals for $\mathrm{pH}$ adjustment. Thus, for the sake of providing safe water in an economical and safe way, it is important to consider softening efficiency at neutral $\mathrm{pH}$. From the data, it was revealed that around neutral $\mathrm{pH}$, efficiency was constant with the average removal efficiency of $60 \%$ for synthetic water and $44 \%$ for field collected water.

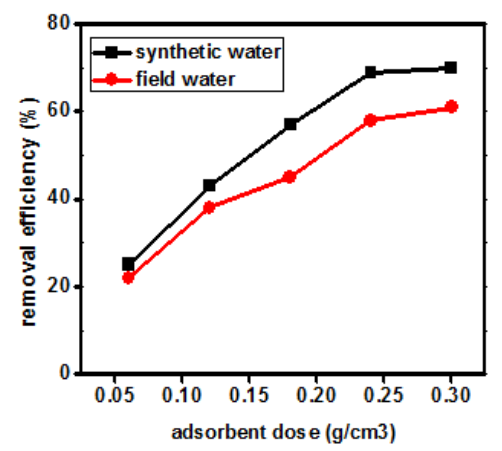

Fig 6. Effect of adsorbent dose on hardness removal by CSAC: contact time $=4$ hours, hardness $864 \mathrm{mg} / \mathrm{L}, \mathrm{pH}=6.3$, temperature $=303 \mathrm{~K}$

\subsection{Effect of Adsorbent dose on Hardness Removal}

The effect of adsorbent dose on hardness removal is shown in Fig. 6. Adsorbent dose was varied between 0.06 to $0.3 \mathrm{~g} / \mathrm{cm}^{3}$ and it was indicated that removal efficiency increases with increase in the CSAC dose up to $0.24 \mathrm{~g} / \mathrm{cm}^{3}$ where further dose increase yields negligible adsorption. Greater availability of exchangeable sites at higher concentration of adsorbent is the reason for the increase in hardness removal with the increase in adsorbent dose [23]. According to Chakrabarty and Sarma [24], after a certain dose of adsorbent, the maximum adsorption is attained and hence the amount of ions remain constant even with further addition of dose of adsorbent. That's why beyond 0.24 $\mathrm{g} / \mathrm{cm} 3$ the adsorption found to be constant.

\subsection{Adsorption Isotherms Study}

For the purpose of understanding the distribution of hardness ions between the liquid phase and the solid phase, the Langmuir and Freundlich isotherm models were used. Langmuir isotherm curve for adsorption of hardness ions onto CSAC is shown in fig. 7.

Langmuir isothermal model is described by the following equation:

$$
q_{e}=\frac{a b C_{e}}{\left(1+b C_{e}\right)}[25]
$$

Where, $\mathrm{q}_{\mathrm{e}}$ is the amount of hardness adsorbed $(\mathrm{mg} / \mathrm{g}), \mathrm{C}_{\mathrm{e}}$ is the equilibrium hardness $(\mathrm{mg} / \mathrm{L})$, $a$ and $\mathrm{b}$ are Langmuir

\section{Langmuir isotherm curve}

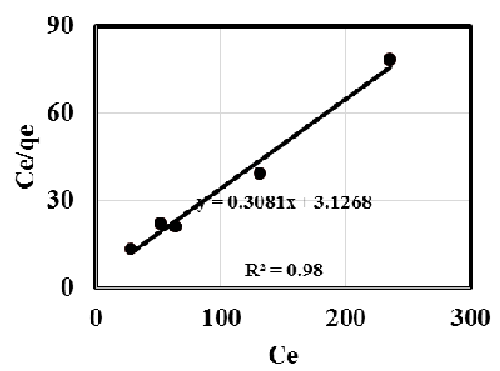

Fig 7. Langmuir isothermal curve for adsorption of hardness ions onto CSAC: contact time $=15$ hours, adsorbent dose $=0.16 \mathrm{~g} / \mathrm{cm}^{3}, \mathrm{pH}=6.3$, temperature $=303 \mathrm{~K}$

\section{Freundlich isotherm curve}

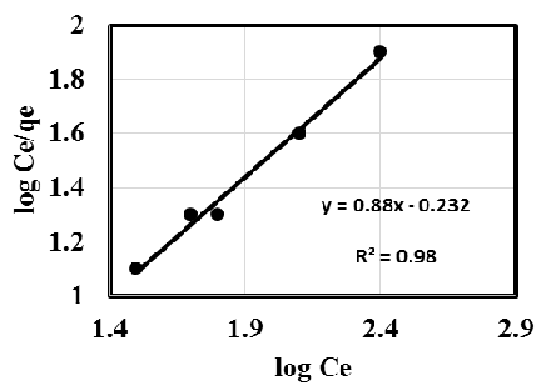

Figure 8. Freundlich isotherm curve for adsorption of hardness ions onto $C S A C$ : contact time $=4$ hours, adsorbent dose $=0.16 \mathrm{~g} / \mathrm{cm}^{3}, p H=6.3$, temperature $=303 \mathrm{~K}$ 
constants related to capacity and energy of adsorption respectively. The plot of $\mathrm{C}_{\mathrm{e}} / \mathrm{q}_{\mathrm{e}}$ against $\mathrm{C}_{\mathrm{e}}$ gave a straight line with a slope $1 / \mathrm{ba}$. The dimensionless constant separation factor $\mathrm{R}_{\mathrm{L}}$ can be used to define essential features of Langmuir isotherm model. $\mathrm{R}_{\mathrm{L}}$ is expressed by the following equation

$$
R_{L}=\frac{1}{\left(1+b C_{i}\right.}[26]
$$

Where, $C_{i}$ is the initial hardness $(\mathrm{mg} / \mathrm{L})$ and ' $b$ ' is the Langmuir constant (in $\mathrm{g} / \mathrm{L}$ ). According to Hameed, et al. [26], the separation factor $\mathrm{R}_{\mathrm{L}}$ indicates the isotherm's shape and the nature of the adsorption process, that is, unfavorable $\left(\mathrm{R}_{\mathrm{L}}>1\right)$, linear $\left(\mathrm{R}_{\mathrm{L}}=1\right)$, favorable $\left(0<\mathrm{R}_{\mathrm{L}}<1\right)$ and irreversible $\left(R_{L}=0\right)$. In the present study, the values of $R_{L}$ was found to be 0.013 , indicating that the adsorption process is favourable for the removal of hardness ions.

The Freundlich isotherms model is expressed by the following equation:

$$
\log q_{e}=\log K_{F}+\left(\frac{1}{n}\right) \log C_{e}[15]
$$

Where, $\mathrm{q}_{\mathrm{e}}$ is the amount of hardness adsorbed $(\mathrm{mg} / \mathrm{g}), \mathrm{C}_{\mathrm{e}}$ is the equilibrium hardness $(\mathrm{mg} / \mathrm{L}), \mathrm{K}_{\mathrm{F}}\left(\mathrm{mg} / \mathrm{g}(\mathrm{L} / \mathrm{mg})^{1 / \mathrm{n}}\right)$ and $\mathrm{n}$ are Freundlich constant indicating adsorption capacity and favorability of adsorption. Fig. 8 shows Freundlich isotherm curve for adsorption of hardness ions onto CSAC.

$\mathrm{R}^{2}$ values indicate that both Freundlich and Langmuir isotherm models represent adsorption of hardness ions onto CSAC.

\section{Conclusion}

Based on the results obtained in the present study, it is clear that CSAC is effective in water softening. Since the coconut shells are locally available, especially in coast regions where hardness problem is prevailing, then, CSAC adsorbents are expected to be economically feasible for removal of hardness from groundwater. Langmuir adsorption isotherm model indicated that the adsorption of hardness ions onto CSAC is favorable. Although the removal at $\mathrm{pH} 12$ is high, this will necessitate the use of other $\mathrm{pH}$ correcting reagents which will make the process uneconomical and leads to the introduction of chemicals contaminants in softened water. Therefore, adsorption at neutral $\mathrm{pH}$, though less effective than at a $\mathrm{pH}$ of 12 , is preferred due to economic and water safety reasons.

\section{References}

[1] Meena, K. S., Gunsaria, R. K., Meena, K., Kumar, N. and Meena, P. L., 2011. The Problem of Hardness in Ground Water of Deoli Tehsil (Tonk District) Rajasthan. Journal of Current Chemical \& Pharmaceutical Sciences, 2(1): 50-54

[2] Knivsland, S. M., 2012. Water Chemistry in the Bahi-Manyoni Basin in Tanzania. Reprosentralen, University of Oslo
[3] Napacho, Z. A., \& Manyele, S. V., 2010. Quality Assessment of Drinking Water in Temeke District (part II): Characterization of Chemical Parameters. African Journal of Environmental Science and Technology, 4(11): 775-789.

[4] Agostinho, L. C. L., Nascimento, L. and Cavalcanti, B. F., 2012. Water Hardness Removal for Industrial Use. Application of the Electrolysis Process. 1:460. doi:10.4172/scientificreports.460

[5] Seo, S. J., Jeon, H., Lee, L. K., Kim, G. Y., Park, D., Nojima, H., Lee, J. and Hyeon, S., 2010. Investigation on Removal of Hardness Ions by Capacitive Deionization (CDI) for Water Softening Applications. Water research, 44: 2267-2275

[6] Johnson, R and Scherer, T., 2012. Drinking Water Quality. Testing and Interpreting Your Results: NDSU Extension Service

[7] WHO, 2011. Hardness in Drinking-water Background Document for Development of WHO: Guidelines for Drinking-water Quality. WHO Press

[8] Manahan, S. E. (2000). Environmental Chemistry. (7th ed) Boca Raton: CRC Press LLC

[9] Malakootian, M., Mansoorian, H. J., \& Moosazadeh, M., 2010. Performance Evaluation of Electrocoagulation Process using Iron-rod Electrodes for Removing Hardness from Drinking Water. Desalination, 255(1): 67-71

[10] Dow Water \& Process Solutions, 2013. FILMTEC ${ }^{\text {TM }}$ Reverse Osmosis Membranes Technical Manual

[11] Frankel, V. S. (2011) Seawater Desalination: Trends and Technologies. USA: Kennedy/Jenks Consultants

[12] Grassi, M., Kaykioglu, G., Belgiorno, V., \& Lofrano, G. (2012). Removal of emerging contaminants from water and wastewater by adsorption process. In Emerging Compounds Removal from Wastewater (pp. 15-37). Springer Netherlands

[13] Window on State Government (1996), Specification for Floor Finish Remover-concentrate, Texas Specification No. 485-54-09A. Retrieved from http://www.window.state.tx.us/procurement/pub/specificatio ns-library/485/54-09a/

[14] Hanumantharao, Y., Kishore, M., \& Ravindhranath, K. (2011). Preparation and development of adsorbent carbon from Acacia farnesiana for defluoridation. International Journal of Plant, Animal and Environmental Sciences, 1(3), 209-223.

[15] Gulipalli, C. S., Prasad, B., Wasewar, K. L., (2011) Batch Study, Equilibirum and Kinetics of Adsorption of Selenium Using Rice Husk Ash (RHA). Journal of Engineering Science and Technology, 6 (5), 586-605

[16] Desta, M. B., (2013) Batch Sorption Experiments: Langmuir and Freundlich Isotherm Studies for the Adsorption of Textile Metal Ions onto Teff Straw (Eragrostis tef) Agricultural Waste. Journal of Thermodynamics Volume 2013, Article ID 375830, 6 pages

[17] Cash, D., (2008) EDTA Titrations 2: Analysis of Calcium in a Supplement Tablet; Analysis of Magnesium in Epsom Salt; Hardness of Water. Mohawk College of Applied Arts and Technology. 
[18] Srivastava, V. C., Mall, I. D., \& Mishra, I. M. (2008). Adsorption of toxic metal ions onto activated carbon: Study of sorption behaviour through characterization and kinetics. Chemical Engineering and Processing: Process Intensification, 47(8), 1269-1280

[19] Sherene, T. (2010). Mobility and transport of heavy metals in polluted soil environment. Biological Forum - An International Journal, 2(2): 112-121

[20] Wong MH, Pang J, Chan GSY, Zhang J, Liang J (2003). Physiological aspects of vetiver grass for rehabilitation in abandoned metalliferous mine wastes. Chemosphere $5: 1559-1570$

[21] Hydrology Project, (1999). Understanding hydrogen ion concentration $(\mathrm{pH})$. New Delhi: World Bank \& Government of The Netherlands funded

[22] Jimoh, T. O., Buoro, A. T., \& Muriana, M. (2012). Utilization of Blighia sapida (Akee apple) pod in the removal of lead, cadmium and cobalt ions from aqueous solution. Journal of Environmental Chemistry and Ecotoxicology Vol, 4(10), 178-187.
[23] Rolence, C., Machunda, R. L. and Njau, K. N. (2014). Potentials of Agric Wastes Activated Carbon for Water Softening. Research Journal in Engineering and Applied Science 3(3) 199-207

[24] Chakrabarty, S., \& Sarma, H. P. (2012). Defluoridation of contaminated drinking water using neem charcoal adsorbent: kinetics and equilibrium studies. International Journal of ChemTech Research, 4(2).

[25] Sepehr, M. N., Zarrabi, M., Kazemian, H., Amrane, A. Yaghmaian, K. and Ghaffari, H. R., 2013. Removal of Hardness Agents, Calcium and Magnesium, by Natural and Alkaline Modified pumice Stones in Single and Binary Systems. Applied Surface Science, 274: 295-305

[26] Hameed, B. H., Mahmoud, D. K., \& Ahmad, A. L. (2008). Equilibrium modeling and kinetic studies on the adsorption of basic dye by a low-cost adsorbent: Coconut (Cocos nucifera) bunch waste. Journal of Hazardous Materials, $158(1), 65-72$. 